University of Nebraska - Lincoln

DigitalCommons@University of Nebraska - Lincoln

6-1989

\title{
Salsuginus thalkeni n. sp. (Monogenea: Ancyrocephalidae) from Fundulus zebrinus in the South Platte River of Nebraska
}

John J. Janovy Jr.

University of Nebraska - Lincoln, jjanovy1@unl.edu

Tim R. Ruhnke

West Virginia State University, ruhnketr@wvstateu.edu

Terry A. Wheeler

McGill University, terry.wheeler@mcgill.ca

Follow this and additional works at: https://digitalcommons.unl.edu/bioscijanovy

Part of the Parasitology Commons

Janovy, John J. Jr.; Ruhnke, Tim R.; and Wheeler, Terry A., "Salsuginus thalkeni n. sp. (Monogenea:

Ancyrocephalidae) from Fundulus zebrinus in the South Platte River of Nebraska" (1989). John Janovy Publications. 13.

https://digitalcommons.unl.edu/bioscijanovy/13

This Article is brought to you for free and open access by the Papers in the Biological Sciences at DigitalCommons@University of Nebraska - Lincoln. It has been accepted for inclusion in John Janovy Publications by an authorized administrator of DigitalCommons@University of Nebraska - Lincoln. 


\title{
SALSUGINUS THALKENIN. SP. (MONOGENEA: ANCYROCEPHALIDAE) FROM FUNDULUS ZEBRINUS IN THE SOUTH PLATTE RIVER OF NEBRASKA
}

\author{
J. Janovy, Jr., T. R. Ruhnke, and T. A. Wheeler* \\ School of Biological Sciences, University of Nebraska-Lincoln, Lincoln, Nebraska 68588-0118
}

ABSTRACT: Salsuginus thalkeni n. sp. (Monogenea: Ancyrocephalidae) is described from the gills of the plains killifish, Fundulus zebrinus, in the South Platte River of Nebraska. Salsuginus thalkeni is distinguished from previously described species by measurements of sclerotized parts and by proportions (measurement ratios), differences between dorsal and ventral hamuli, and angles between deep and superficial hamulus roots.

A number of papers have reported ecological observations on a monogenean parasitizing Fundulus zebrinus Garman (=Fundulus kansae) in the South Platte River of Nebraska. This species of helminth has been called "Urocleidus fundulus" by Adams $(1985,1986)$ and Janovy and Hardin (1987), and Salsuginus sp. by Janovy and Hardin (1988). A thorough study of the ancyrocephalid monogeneans parasitizing Fundulus species was presented by Murith and BeverleyBurton (1985), who reviewed and evaluated taxonomic characters, synonymized some of the helminth species, assigned them all to the genus Salsuginus, and provided advice on the identification of specimens from various hosts. The present description is intended to resolve the taxonomic position and nomenclature of the ancyrocephalid worms that have been used in previous ecological studies (Adams, 1985, 1986; Janovy and Hardin, 1987, 1988), according to the criteria of Murith and Beverley-Burton (1985).

\section{MATERIALS AND METHODS}

Fish were collected from the South Platte River, 4 km east of Roscoe, Keith County, Nebraska. Three hundred ten fish, ranging from 39 to $85 \mathrm{~mm}$ long, collected between May 1986 and July 1988, were examined.

Gills were excised and placed in $1 \%$ chloral hydrate for up to $1 \mathrm{hr}$. Worms were removed with insect pin probes, fixed in AFA, washed in $70 \%$ ethanol, and either (1) cleared, and temporarily mounted, in glycerin; (2) cleared in glycerin and mounted in glycerin jelly; (3) stained in acetocarmine or hematoxylin, dehydrated, cleared in xylene, and mounted in Permont under cover glasses ringed with Canada balsam, or (4) dehydrated, cleared in xylene, and mounted in Canada balsam.

Received 29 February 1988; revised 1 February 1989; accepted 1 February 1989.

* Department of Environmental Biology, University of Guelph, Guelph, Ontario, Canada N1G 2W1.
Sixty-three specimens were studied, 35 of which were temporarily mounted in glycerin for measurement of sclerotized parts. Measurements were taken according to the protocol of Murith and Beverley-Burton (1985). In addition, ratios of $d / c$ and $x / y$ measurements were calculated in order to distinguish the present species from previously described worms whose hamuli had proportions that appeared to be different from those of $S$. thalkeni. Measurements are given in $\mu \mathrm{m}$ as mean with range, standard deviation, and number of measurements in parentheses. For comparative purposes the angle between superficial and deep roots was determined from camera lucida drawings and from published figures of previously described species by extending the lines along which measurements $c$ and $d$ were taken and measuring the resulting angles with a protractor. Drawings in Figures 1-7 were made with the aid of a camera lucida.

\section{DESCRIPTION \\ Salsuginus thalkeni n. sp. (Figs. 1-7)}

Diagnosis: Ancyrocephalidae with the characters of the genus Salsuginus as defined by Murith and Beverley-Burton (1985). Body 409 (336-480, 36.9, 10) long by $117(106-144,12.4,10)$ in maximum width (midbody); haptor $54(48-58,5.1,10)$ long by $74(58-86$, $7.8,10)$ wide; pharynx $32(27-38,2.9,31)$ in transverse diameter. Both hamuli with long, thin, curved blade and superficial root larger than deep root (Figs. 2, 3). Dorsal (Fig. 2) and ventral (Fig. 3) hamuli similar in shape, except that angle between deep and superficial root is greater, and the superficial root is proportionately shorter than the deep root, in the dorsal hamuli than in the ventral. Standard hamuli measurements (see Murith and Beverley-Burton, 1985): Dorsal: $a=$ $19.8(18-25,1.4,35), b=15.7(14-20,1.5,35), c=$ $4.2(3-5,0.5,35), d=9.3(7-12,1.1,35), e=7.1(6-$ $10,1.3,35), x=11.6(8-15,5.4,35), y=13.3(8-16$, $4.2,35), d / c$ ratio mean (standard deviation, $\mathrm{n})=2.3$ $(0.5,35), x / y$ ratio $=1.0(0.1,35)$. Ventral: $a=23.1$ $(19-26,2.2,35), b=18.6(15-20,1.3,35), c=3.0(2-$ $4,0.4,35), d=11.1(9-14,1.4,35), e=7.5(6-9,0.7$, $35), x=12.1(9-16,4.2,35), y=13.2(10-16,2.6$, $35), d / c$ ratio $=3.9(1.0,35), x / y$ ratio $=1.0(0.1,35)$. Dorsal bar $19.3(17-21,1.1,35)$ long by $3.6(3-5,0.5$, $35)$ wide. Ventral bar $22.2(20-27,5.9,35)$ long by 3.6 (3-6, 0.6, 35). Larval hooks $12.3(11-13,0.5,35)$.

Penis tubular, $22.3(18-28,2.3,36)$ long (straight 

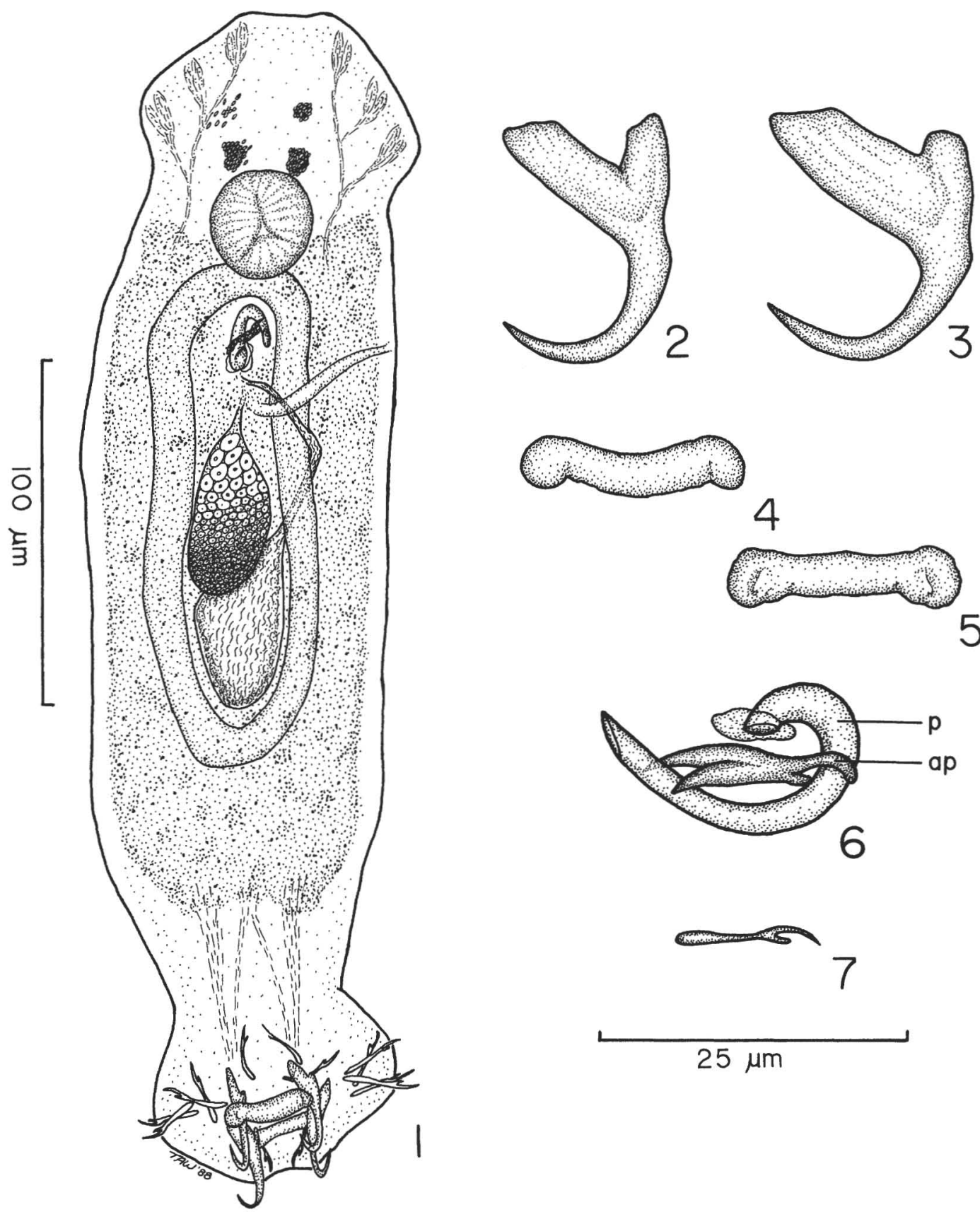

5
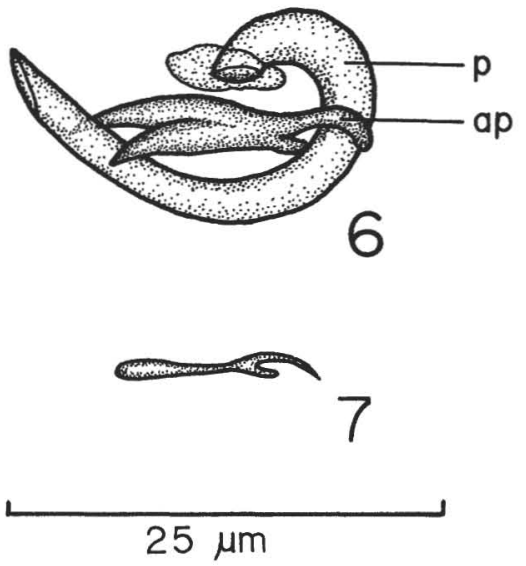

Figures 1-7. Salsuginus thalkeni $\mathrm{n}$. sp. 1. Whole worm, ventral view. 2. Dorsal hamulus. 3. Ventral hamulus. 4. Dorsal bar. 5. Ventral bar. 6. Male copulatory structures. 7. Larval hook. $p=$ penis; ap $=$ accessory piece.

line base to tip), distal aperture $2.0(2-3,0.2,36)$ wide. Accessory piece $19.7(15-24,1.4,37)$ long, terminal end with pointed branches (Fig. 6) and bilobed proximal end. Entire accessory piece lies within the outside curve of the penis and supports the distal end of the latter.

\section{Taxonomic summary}

Type host: Fundulus zebrinus Garman, 1895; the plains killifish.

Type locality: U.S.A., Nebraska, Keith County, South Platte River $4 \mathrm{~km}$ east of Roscoe.

Specimens deposited: One holotype (USNM No. 
80229), 13 paratypes (USNM No. 80230), and 12 topotypes (USNM No. 80458) have been deposited in the United States National Museum Helminthological Collection, Beltsville, Maryland. Fourteen paratypes (UNSM No. 19967 and UNSM No. 19968) and 15 topotypes (UNSM No. 20721) have been deposited in the H. W. Manter Laboratory, University of Nebraska State Museum, Lincoln, Nebraska 68588-0514.

Etymology: The name thalkeni is given in honor of the land owner, Mr. Darrel Thalken of Roscoe, who has allowed faculty members and students from the University of Nebraska Cedar Point Biological Station to use his property for teaching, research, and access to the South Platte River.

\section{Remarks}

Salsuginus thalkeni is similar to Salsuginus angularis (Mueller, 1934) Beverley-Burton, 1984, Salsuginus spirae (Williams, 1980) Murith and Beverley-Burton, 1985, Salsuginus bermudae Rand and Wiles, 1987, Salsuginus bahamianus (Hanek and Fernando, 1972) Murith and Beverley-Burton, 1985, Salsuginus seculus (Mizelle and Arcadi, 1945) Murith and BeverleyBurton, 1985, and Salsuginus heterocliti Murith and Beverley-Burton, 1985, in having dorsal hamuli smaller than ventral ones, and different from Salsuginus umbraensis (Mizelle, 1938) Murith and BeverleyBurton, 1985 and Salsuginus fundulus (Mizelle, 1940) Beverley-Burton, 1984, in which the dorsal and ventral hamuli are approximately the same size. Salsuginus thalkeni differs from $S$. angularis in having hamuli that are proportionately longer (dorsal $x / y=1.0$, ventral $x / y=1.0$ in $S$. thalkeni vs. 1.3 and 1.2 , respectively, in $S$. angularis), and in having proportionately shorter superficial roots $(d / c=2.3$ and 3.9 vs. 3.3 and 4.3 , respectively). The new species differs from $S$. heterocliti and $S$. spirae in having a shorter dorsal bar, and from $S$. heterocliti in having smaller dorsal hamuli. Salsuginus thalkeni hamuli are dimorphic in that not only are their sizes significantly different, but the $d / c$ ratios and the angles formed by their deep and superficial roots are different (latter is termed the $d / c$ angle; dorsal approximately $60-70^{\circ}$, ventral $45-55^{\circ}$ ). In the case of $d / c$ angle, $S$. thalkeni differs from $S$. angularis, $S$. bermudae, $S$. umbraensis, and $S$. heterocliti, whose respective dorsal and ventral root angles are approximately equal, and from $S$. seculus, $S$. bahamianus, and $S$. spirae, in which the $d / c$ angle of the ventral hamuli is larger than that of the dorsal.

The accessory piece of the male copulatory apparatus appears distinctive, but this distinctiveness is not easy to express in terms of measurements (Murith and Beverley-Burton, 1985; see their figs. 15, 17). The accessory piece of $S$. thalkeni differs from those of most other Salsuginus species in lacking the subterminal lobes, whereas the proximal lobes are longer than those of other species (cf. Fig. 6 and figs. 15, 17 of Murith and Beverley-Burton, 1985). In the present material, the morphology of both the dorsal and ventral bars is quite variable in the extent of curvature, degree of "knobbiness," and depth and position of grooves.

\section{DISCUSSION}

Previous describers of Salsuginus species have used mainly sizes of hamuli and shapes of the accessory piece (Mizelle and Arcadi, 1945; Mur- ith and Beverley-Burton, 1985; Rand and Wiles, 1987). In this description, an attempt was made to add proportions, for example through the use of $d / c$ ratios and angles between deep and superficial roots, as well as "meta-measurements" such as differences between dorsal and ventral hamuli, to the set of characters being considered. This attempt was made in order to avoid a problem mentioned by Rand and Wiles (1987), namely that of morphometric similarity in the face of morphological difference. Thus, Rand and Wiles (1987) showed that hamuli from Salsuginus species could be of the same size without being of the same shape and suggested that shape be used as a taxonomic character. Murith and Beverley-Burton (1985) demonstrated clearly that accessory pieces and hamuli with broadly overlapping size ranges (their table 2) can have quite distinct morphologies (their figs. 17, 18). In the present study, use of ratios, root angles, and dorsal/ventral hamuli differences provides information not given in all previous descriptions except indirectly through drawings. It is hoped that such information will be gathered and reported directly for future new Salsuginus species so that eventually an evaluation can be made of the usefulness of "meta-measurements" as taxonomic and identification characters.

Previous descriptions of Salsuginus species have referred to internal morphology in only a brief and cursory manner, possibly because of problems in observing and evaluating structures of type material (cf. Rand and Wiles, 1987). Even when detailed information on internal anatomy is available (e.g., Murith and Beverley-Burton [1985] on $S$. angularis), the evident difficulty of gathering equivalent observations on other species, as well as the highly variable manner in which such information is reported, seems to have reduced internal anatomical details to a subordinate status as taxonomic characters at the species level in this genus. For this reason, the present description is based on hamuli and sclerotized portions of the male reproductive system.

\section{ACKNOWLEDGMENTS}

The authors thank Mr. Darrel Thalken, Roscoe, Nebraska, for use of private land; Profs. Mary Lou Pritchard and Mary Beverley-Burton for advice; and Drs. A. Joern and L. Vescio for use of Cedar Point Biological Station facilities.

\section{LITERATURE CITED}

ADAMS, A. 1985. Parasites on the gills of the plains killifish, Fundulus kansae, in the South Platte Riv- 
er, Nebraska. Transactions of the American Microscopical Society 104: 278-284.

- 1986. The parasite community on the gills of Fundulus kansae (Garman) from the South Platte River, Nebraska (USA). Acta Parasitologica Polonica 31: 47-54.

JanOVy, J., JR., AND E. L. Hardin. 1987. Population dynamics of the parasites in Fundulus zebrinus in the Platte River of Nebraska. Journal of Parasitology 73: 689-696.

, AND - 1988. Diversity of the parasite assemblage of Fundulus zebrinus in the Platte River of Nebraska. Journal of Parasitology 74: 207213.

Mizelle, J. D., AND J. A. Arcadi. 1945. Studies on monogenetic trematodes XIII. Urocleidus seculus, a new species of Tetraonchinae from the vivipa- rous top minnow, Gambusia affinis affinis (Baird and Girard). Transactions of the American Microscopical Society 64: 293-296.

Murith, D., AND M. BeVERLey-Burton. 1985. Salsuginus Beverley-Burton, 1984 (Monogenea: Ancyrocephalidae) from Cyprinodontoidea (Atheriniformes) in North America with descriptions of Salsuginus angularis (Mueller, 1934) BeverleyBurton, 1984 from Fundulus diaphanus and Salsuginus heterocliti $\mathrm{n}$. sp. from $F$. heteroclitus. Canadian Journal of Zoology 63: 703-714.

RAND, T. G., AND M. Wiles. 1987. Salsuginus bermudae sp. n. (Monogenea: Ancyrocephalidae) from Fundulus bermudae Gunther and Gambusia affinis (Baird and Girard) in Bermuda. Canadian Journal of Zoology 65: 1847-1852. 